\title{
Disseminated Mycobacterium avium infection in a young woman with sickle cell disease and iatrogenic iron overload
}

\author{
Pouria Hosseini ${ }^{1}$, Yogamaya Mantha ${ }^{2}$, Shannon J. Koh ${ }^{3}$, Gebre K. Tseggay ${ }^{3}$, Jyothi K. Baby ${ }^{1}$, Rahul Gill ${ }^{1}$, Mark \\ Feldman*1 \\ ${ }^{1}$ Internal Medicine Department, Texas Health Presbyterian Hospital, Dallas, TX, USA \\ ${ }^{2}$ Department of Cardiology, University of Texas Health Sciences, San Antonio, TX, USA \\ ${ }^{3}$ Division of Infectious Disease, Texas Health Presbyterian Hospital, Dallas, TX, USA
}

Received: July 27, 2021

DOI: $10.5430 /$ crim.v8n2p5
Accepted: September 8, 2021

Online Published: October 20, 2021

\begin{abstract}
A 29-year-old woman with known sickle cell disease (SCD) and iatrogenic iron overload presented to the emergency department with a recurrent pain crisis and fever. Blood cultures obtained at a recent prior admission for the same complaints grew $\mathrm{M}$ avium. Bone marrow biopsy revealed non-caseating granulomas, but stains for mycobacteria and fungi were negative. Disseminated nontuberculous mycobacterial infections (NTMIs) occur almost exclusively in immunosuppressed patients. SCD is not considered a risk factor for the development of disseminated NTMIs, making diagnosis challenging in this population. However, a number of case reports describing disseminated NTMIs in patients with SCD have been published. This case adds to the current literature, suggesting SCD with iatrogenic iron overload is a possible risk factor for disseminated NTMIs. Potential mechanisms for this increased risk include 1) functional asplenia, 2) iatrogenic iron overload, 3) chronic indwelling central venous catheters, and 4) hydroxyurea use. Further investigation is required to describe the strength and mechanism of the relationship between SCD and disseminated NTMIs.
\end{abstract}

Key Words: Sickle cell disease, Iron overload, Disseminated mycobacterium avium, Immunocompromised state

\section{INTRODUCTION}

Sickle cell disease (SCD) is caused by a point mutation in the gene encoding the $\beta$ chain of the hemoglobin molecule. Patients with homozygous mutations produce abnormal hemoglobin which polymerizes and causes a rigid deformity of the red blood cell. Deformed cells cannot efficiently flow through small vascular channels leading to infarction of tissues. Sickle cell disease is characterized by frequent infarction of tissues including brain, lung, liver, spleen, kidney, and bone marrow; the latter of which is responsible for acute pain crises. Hemolysis of deformed intravascular erythrocytes results in anemia requiring frequent transfusions, ultimately leading to iatrogenic iron overload. ${ }^{[1]}$

Disseminated non-tuberculous mycobacterial infections (NTMIs) were first described in 1907. ${ }^{[2]}$ The most common culprit is mycobacterium-avium complex. ${ }^{[2]}$ Disseminated NTMIs occur almost exclusively as opportunistic infections in the severely immunosuppressed, such as patients with acquired immunodeficiency syndrome (AIDS), primary im-

*Correspondence: Mark Feldman; Email: marknmnfeldman@gmail.com; Address: 8440 Walnut Hill Ln Ste 700, Dallas, TX 75231, USA. 
munodeficiency disease, and those taking immunosuppressive medications. ${ }^{[3]}$ The interleukin 12 - interferon $\gamma$ (IL12IFN $\gamma$ ) pathway is critical to mycobacterial immunity. Primary and acquired immunodeficiencies involving the IL12IFN $\gamma$ pathway have been associated with disseminated NTMIs. ${ }^{[4]}$ SCD, however, is not considered a risk factor for the development of disseminated NTMIs; leading to low physician suspicion and making diagnosis difficult in this population. ${ }^{[3]}$ A handful of case reports describing disseminated NTMIs in patients with SCD were published between 2006 and 2017. [5-9] This report adds to the current literature, suggesting that SCD with iatrogenic iron overload is a possible risk factor for disseminated NTMIs.

\section{Case presentation}

A 29-year-old African American woman with known SCD (HbSS) presented to the emergency department with subjective fever, progressive weakness, dark urine, shortness of breath, and generalized pain for three weeks. She denied cough, chills, weight loss, chest pain, shortness of breath, abdominal pain, nausea, vomiting, diarrhea, dysuria, or any other symptoms. Her medical history included known SCD, complicated by iatrogenic iron overload. A chronic indwelling central venous catheter (CICVC) had been placed in 2016. A systolic murmur had been previously documented without evidence of structural abnormalities or endocarditis. One month prior to this presentation, the patient had been admitted to our hospital for sickle cell pain crisis and fever of unknown origin. Infectious work-up was negative at the time. Her home medications include cholecalciferol 2000 units daily, hydroxyurea (HU) $500 \mathrm{mg}$ twice daily, folic acid $1 \mathrm{mg}$ daily, and hydrocodone-acetaminophen $10-325 \mathrm{mg}$ as needed for pain.

Vital signs revealed tachycardia (107 beats per minute) and hypoxia ( $\mathrm{SpO} 285 \%$ on room air), requiring 4L O2 via nasal cannula. Her blood pressure and temperature were normal. She was chronically ill appearing, thin, and in mild distress due to generalized pain. Conjunctival icterus and pallor were present. Cardiac exam revealed a regular rhythm and a faint systolic murmur. A CICVC was present in the chest wall. The rest of the physical examination was unremarkable.

\subsection{Hospital Course}

Pertinent laboratory tests on admission included total white blood cell count of 14,110/uL, absolute neutrophil count of $8,920 / \mathrm{uL}$, hemoglobin $4.6 \mathrm{~g} / \mathrm{dL}$, reticulocyte count of $17.3 \%$, and ferritin greater than $33,500 \mathrm{ng} / \mathrm{mL}$. Acid fast bacilli (AFB) blood culture from the recent prior admission had turned positive for pan-susceptible M. avium four days prior to this admission.

6
The patient developed several episodes of fever during her hospitalization. Repeat blood and sputum cultures also grew M. avium. Human immunodeficiency virus (HIV) test was negative. Autoantibodies to interferon $\gamma$ were absent. The Invitae primary immunodeficiency panel revealed variants of uncertain significance, but no mutations associated with immunodeficiency.

Computed tomography (CT) of the chest showed diffuse rounded peripheral and irregular ground-glass infiltrates predominantly in the lower lobes (Figure 1a). Peripheral blood smear showed microcytic and hypochromic red blood cells containing iron deposits (see Figure 1b). Bone marrow biopsy revealed markedly increased iron storage and frequent non-caseating granulomas (see Figure 1c-d). Bone-marrow staining and culture was negative for organisms including AFB.

\subsection{Treatment}

The patient was started on azithromycin, ethambutol, and rifampin. Her hospital course was complicated by continued hemolytic anemia and difficulty obtaining U-negative blood. She was discharged in stable condition on hospital day \#20. The patient has subsequently been re-hospitalized for high fevers. AFB blood cultures persistently grew M. avium despite 3 months of appropriate treatment.

\section{Discussion}

Disseminated NTMIs are challenging to diagnose, particularly in the absence of known immune dysfunction such as AIDS, IL12-IFN $\gamma$ pathway dysfunction, or immunosuppressive medications. A review of 36 non-HIV cases showed the average time to diagnosis was 5.3 months. ${ }^{[3]}$ In our patient, the time to diagnosis was 10 weeks. Given the high mortality associated with this disease, high clinical suspicion is required to make a timely diagnosis and administer lifesaving antimicrobial agents. ${ }^{[3,4]}$ A handful of case reports describing disseminated NTMIs in patients with SCD have been published. ${ }^{[6-10]}$ Our report adds to the current literature, suggesting that SCD with iatrogenic iron overload may be a risk factor for disseminated NTMIs. The mechanism of this risk is unclear. Some possible factors that may increase SCD patients' risk for mycobacterial infection include: functional asplenia, iatrogenic iron overload, CICVCs, HU use.

The spleen is the largest lymphoid organ in the body. It has numerous important functions including the regulation of inflammation, filtration and clearance from the blood, adaptive immunity, and innate immunity. ${ }^{[11]}$ As a result, asplenic patients suffer from more frequent and severe infections with encapsulated organisms and intra-erythrocytic parasites. ${ }^{[11,12]}$ SCD strongly affect the spleen both acutely 
in the form of acute splenic sequestration crisis, and chronically in the form of progressive vasoocclusion and infarction. ${ }^{[13,14]}$ As a result, by age 6-8 years children with SCD have a non-functioning spleen. ${ }^{[15]}$ No association between asplenia and mycobacterial infections has been documented.

Iron is an essential trace element, and its sequestration is a key part of the innate immune system. In healthy patients, iron is permanently sequestered from mucosal surfaces, non-

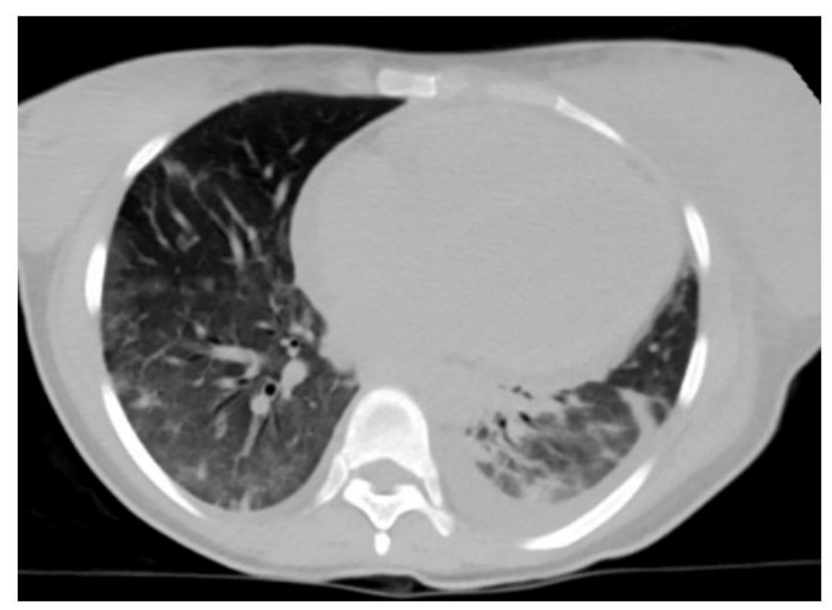

(a)

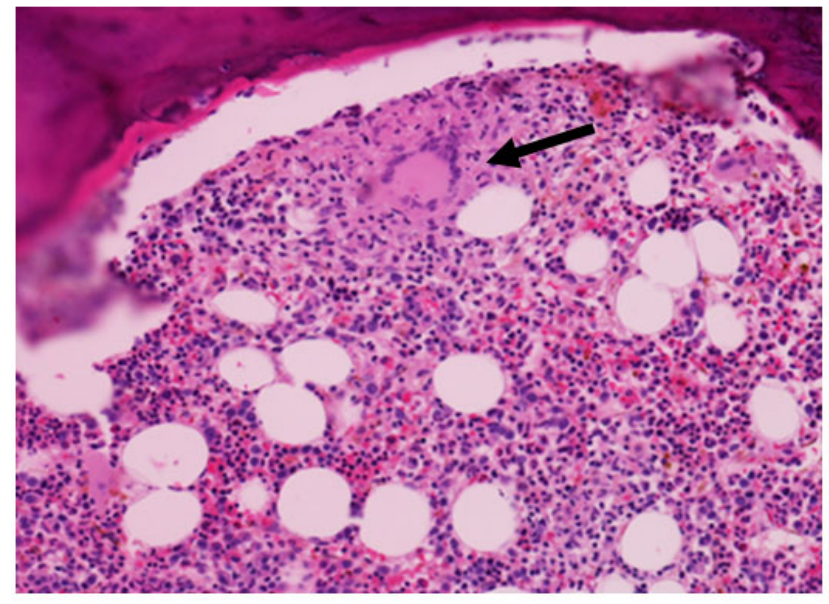

(c) transferrin bound iron is strongly regulated, and extracellular fluid is depleted of iron during inflammation or infection. These mechanisms inhibit microbial growth by limiting the availability of the essential element iron. ${ }^{[16]}$ Correspondingly, patients with iron overload are at increased risk of infection with a variety of organisms including V. vulnificus, Y. enterocolitica, Y. pseudotuberculosis, L. monocytogenes, and HIV. ${ }^{[17-20]}$

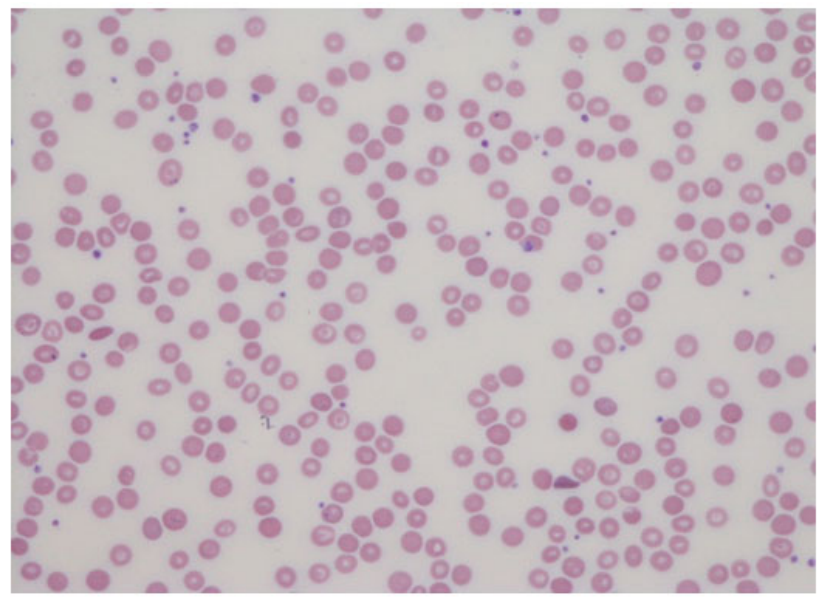

(b)

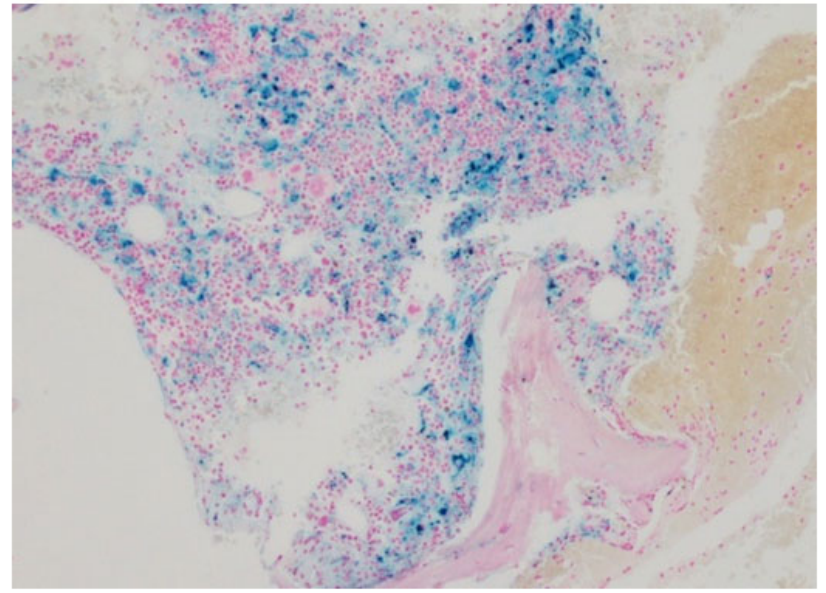

(d)

Figure 1. (a) CT image showing diffuse, rounded, peripheral and irregular ground-glass infiltrates predominantly in the lower lobes. (b) Wright-Giemsa stained peripheral blood smear showing microcytic and hypochromic red blood cells and target cells. Magnification $\times 400$. (c) Bone marrow biopsy showing non-caseating granuloma with Langerhan's type multinucleated giant cell (arrow). Magnification $\times 200$. (d) Prussian blue staining of bone marrow aspirate shows iron deposition.

Regarding mycobacterial infections specifically, a post-hoc analysis of 714 individuals from southern Africa showed that those with severe iron overload were 17 times more likely to die from tuberculosis. ${ }^{[21]}$ The mechanism of iron overload in the aforementioned study was increased dietary ingestion, and the prevalence of sickle cell disease was not reported. It remains to be seen if these results can be generalized to other mycobacterial infections.

CICVCs are used in SCD to facilitate chronic transfusions and acute management. CICVCs increase the risk of blood stream infections (BSIs). ${ }^{[22]}$ This risk seems to be magnified 
in SCD patients. In a study of 47 SCD patients, CICVCs were the source of BSIs in $41 \%$ of patients, compared with $11 \%$ in the general population. ${ }^{[22]}$ Regarding mycobacterial infections specifically, a small study of 16 patients suggested that CICVCs increase the risk for blood-stream NTMIs. ${ }^{[10]}$ The same study also suggested that the presence of SCD was a risk factor for NTMIs independent of CICVCs. ${ }^{[10]}$

HU is used in SCD because of its ability to increase fetal hemoglobin levels by incompletely understood mechanisms. $^{[23]} \mathrm{HU}$ is a cytotoxic drug that can rarely cause myelosuppression. However, there is no evidence of increased infection risk or clinical immunosuppression with long-term use. ${ }^{[23-25]}$
Other mechanisms by which SCD patients may be susceptible to infections have been described, though the clinical significance of these findings is unclear. ${ }^{[26-29]}$ Further investigation is required to describe the exact strength and mechanism of the relationship between SCD and disseminated NTMIs.

\section{ACKNOWLEDGEMENTS}

The authors thank all the medical staff who dedicated their time and effort to this case.

\section{CONFLiCTS OF INTEREST DisClOSURE}

The authors have declared no conflicts of interest.

\section{REFERENCES}

[1] Piel FB, Steinberg MH, Rees DC. Sickle cell disease. New England Journal of Medicine. 2017; 376(16): 1561-73. PMid:28423290 https://doi.org/10.1056/NEJMra1510865

[2] Koch M, Rabinowitsch L. Die Tuberkulose der Vögel und ihre Beziehungen zur Säugetiertuberkulose. Virchows Archiv für pathologische Anatomie und Physiologie und für klinische Medizin. 1907; 190(1): 246-541. https://doi .org/10.1007/BF01948490

[3] Horsburgh Jr CR, Mason 3rd U, Farhi DC, et al. Disseminated infection with Mycobacterium avium-intracellulare. A report of 13 cases and a review of the literature. Medicine. 1985;64(1):36-48 PMid:3880852. Available from: https ://doi.org/10.1097/00 005792-198501000-00003

[4] Strnad L, Winthrop K. Mycobacterium avium Complex. Mandell, Douglas, and Bennett's Principles and Practice of Infectious Diseases. 9th ed: Elsevier Health Sciences; 2020. p. 3035-46.

[5] Wu UI, Holland SM. Host susceptibility to non-tuberculous mycobacterial infections. The Lancet Infectious Diseases. 2015; 15(8) 968-80. Available from: https://doi.org/10.1016/S1473-3 099 (15) 00089-4

[6] Thorell EA, Sharma M, Jackson MA, et al. Disseminated nontuberculous mycobacterial infections in sickle cell anemia patients. Journal of Pediatric Hematology/Oncology. 2006; 28(10): 678-81. PMid:17023829. Available from: https: //journals.lww.com/jpho-online/Fulltext/2006/10000/ Disseminated_Nontuberculous_Mycobacterial.8.aspx

[7] Chamsi-Pasha MA, Alraies MC, Alraiyes AH, et al. Mycobacterium avium complex-associated hemophagocytic lymphohistiocytosis in a sickle cell patient: an unusual fatal association. Case Reports in Hematology. 2013; 2013. PMid:23762672. Available from: https: //www.hindawi.com/journals/crihem/2013/291518/

[8] Esnakula AK, Mummidi SK, Oneal PA, et al. Sepsis caused by Mycobacterium terrae complex in a patient with sickle cell disease. Case Reports. 2013; 2013: bcr2013009159. PMid:23645646. Available from: https://casereports.bmj.com/content/2013/bcr-2 013-009159. short

[9] Shemisa K, Jafferjee N, Thomas D, et al. Mycobacterium avium complex infection in a patient with sickle cell disease and severe iron overload. Case Reports in Infectious Diseases. 2014; 2014 PMid:25544913. Available from: https ://www.hindawi.com/jo urnals/criid/2014/405323/
[10] Edun B, Shah A, Durkin M, et al. Non-tuberculous mycobacterial bloodstream infections in patients with indwelling vascular catheters-the role of sickle cell anaemia. Infectious Diseases. 2017; 49(5): 341-6. PMid:27911152. Available from: https: //www . tand fonline.com/doi/full/10.1080/23744235.2016.1262058

[11] Gilsdorf J, Suzanne D. Infections in asplenic patients. Mandell, Douglas, and Bennett's Principles and Practice of Infectious Diseases: Elsevier Health Sciences; 2020. p. 3713-21.

[12] Pearson HA, Spencer RP, Cornelius EA. Functional asplenia in sicklecell anemia. New England Journal of Medicine. 1969; 281(17): 923-6. PMid:5811425. Available from: https ://www.nejm.org/doi/f ull/10.1056/NEJM196910232811703

[13] Piccin A, Smith OP, Murphy C, et al. Splenectomy in sickle cell anaemia: A cause of further crises? British Journal of Haematology. 2009; 145(1): 144-6. PMid:19183187. https://doi.org/10.111 $1 / j .1365-2141.2008 .07564 . x$

[14] Piccin A, Murphy C, Eakins E, et al. Insight into the complex pathophysiology of sickle cell anaemia and possible treatment. European Journal of Haematology. 2019; 102(4): 319-30. PMid:30664257. https://doi.org/10.1111/ejh.13212

[15] Pearson HA, McIntosh S, Ritchey AK, et al. Developmental aspects of splenic function in sickle cell diseases. Blood. 1979; 53(3): 358-65. https://doi.org/10.1182/blood.V53.3.358.358

[16] Ganz T. Iron and infection. International Journal of Hematology. 2018; 107(1): 7-15. Available from: https://link. springer.co $\mathrm{m} /$ article/10.1007\%2Fs12185-017-2366-2

[17] Wright AC, Simpson LM, Oliver JD. Role of iron in the pathogenesis OF Vibrio VULNIFICUS infections. Infection and Immunity. 1981; 34(2): 503-7. PMid:7309236. https://doi.org/10.1128/iai. 34.2.503-507.1981

[18] Piroth L, Meyer $\mathrm{P}$, Bielefeld $\mathrm{P}$, et al. Bactériémie à yersinia ET surcharge En fer. La Revue de Médecine Interne. 1997; 18(12): 932-8. https://doi.org/10.1016/S0248-8663(97)80112-9

[19] van Asbeck BS, Verbrugh HA, van Oost BA, et al. Listeria monocytogenes meningitis and decreased phagocytosis associated with iron overload. BMJ. 1982; 284(6315): 542-4. PMid:6800535. https : //doi.org/10.1136/bmj.284.6315.542

[20] Gordeuk VR, Delanghe JR, Langlois MR, et al. Iron status and the outcome of hiv infection: An overview. Journal of Clinical Virology. 2001; 20(3): 111-5. https ://doi.org/10.1016/S1386-6 $532(00) 00134-7$ 
[21] Gordeuk V, McLaren C, MacPhail A, et al. Associations of iron overload in Africa with hepatocellular carcinoma and tuberculosis: Strachan's 1929 thesis revisited. Blood. 1996; 87(8): 3470-6. PMid:8605366. Available from: https: //ashpublications .org/blood/article/87/8/3470/1246 51/Associations-of-iron-overload-in-Africa-with

[22] Zarrouk V, Habibi A, Zahar JR, et al. Bloodstream infection in adults with sickle cell disease: association with venous catheters, Staphylococcus aureus, and bone-joint. Medicine. 2006; 85(1): 43-8. PMid:16523052. Available from: https ://pubmed.ncbi.nlm.ni h.gov/16523052/

[23] Platt OS. Hydroxyurea for the treatment of sickle cell anemia. New England Journal of Medicine. 2008; 358(13): 1362-9. PMid:18367739. Available from: https://pubmed.ncbi.nlm.ni h.gov/18367739/

[24] Lova L, Groff A, Ravot E, et al. Hydroxyurea exerts a cytostatic but not immunosuppressive effect on T lymphocytes. AIDS. 2005; 19(2): 137-44. PMid:15668538. Available from: https://pubmed.ncbi. nlm.nih.gov/15668538/

[25] Steinberg MH, McCarthy WF, Castro O, et al. The risks and benefits of long-term use of hydroxyurea in sickle cell anemia: A 17.5 year follow-up. American Journal of Hematology. 2010; 85(6): 403-8. PMid:20513116. Available from: https://onlinelibrary.wile y.com/doi/10.1002/ajh. 21699

[26] Kuvibidila SR, Sandoval M, Lao J, et al. Plasma zinc levels inversely correlate with vascular cell adhesion molecule- 1 concentration in children with sickle cell disease. Journal of the National Medical Association. 2006; 98(8): 1263. Available from: https://pubmed.ncbi.nlm.nih.gov/16916123/

[27] Larcher V, Wyke R, Davis L, et al. Defective yeast opsonisation and functional deficiency of complement in sickle cell disease. Archives of Disease in Childhood. 1982; 57(5): 343-6. PMid:7092289. Available from: https ://adc.bmj.com/content/57/5/343. short

[28] Tamouza R, Neonato MG, Busson M, et al. Infectious complications in sickle cell disease are influenced by HLA class II alleles. Human Immunology. 2002; 63(3): 194-9. Available from: https ://doi.org/10.1016/S0198-8859(01)00378-0

[29] [29] Tapazoglou E, Prasad AS, Hill G, et al. Decreased natural killer cell activity in patients with zinc deficiency with sickle cell disease. The Journal of Laboratory and Clinical Medicine. 1985; 105(1): 1922. Available from: https://www.translationalres.com/art icle/0022-2143(85)90083-6/fulltext 